\title{
Erratum to: Exploring Willingness to Participate in Clinical Trials by Ethnicity
}

\author{
Katrina L. Pariera ${ }^{1}$ - Sheila T. Murphy ${ }^{2}$. Jingbo Meng ${ }^{3}$ • Margaret L. McLaughlin ${ }^{2}$
}

Published online: 31 October 2016

(C) W. Montague Cobb-NMA Health Institute 2016

Erratum to: J Racial and Ethnic Health Disparities

DOI:10.1007/s40615-016-0280-6

On page 2, right column, Methods section, third line, change "[survey name removed for blind review]" to "Annenberg National Health Communication Survey".

The online version of the original article can be found at http://dx.doi. org/10.1007/s40615-016-0280-6.

Katrina L. Pariera

klp@gwu.edu

1 Department of Organizational Sciences and Communication, The George Washington University, 600 21st St NW,

Washington, DC 20052, USA

2 Department of Communication, Annenberg School for Communication and Journalism, University of Southern California, Los Angeles, CA, USA

3 Department of Communication, Michigan State University, East Lansing, MI, USA 